\section{The Future of Alcohol Services in Ireland}

Sir, - In view of recent proposals to create new mental health legislation, I present the following recommendations based on my own clinical experience and on a reading of the literature. They are presented as a basis for discussion.

It was intended to present the results of a questionnairebased survey sent to consultant psychiatrists. However, the response rate of $45 \%$ was too low to warrant this.

\section{Recommendations}

1. Early detection of alcohol-related problems should be encouraged in primary care, ${ }^{1}$ general hospitals, ${ }^{2}$ and in psychiatry (wherein psysical signs are often missed $^{3}$ ). This requires a broad definition of alcoholism, such as that given by the W.H.O., ${ }^{4}$ and a high index of clinical suspicion.

2. Greater emphasis on alcohol and ARPs in medical school is essential, despite an already heavy curriculum. Out-patient detoxification, ${ }^{5}$ when it is not done by general practitioners (GPs should manage as many cases as possible), should be carried out locally in centres offering a wide range of psychosocial supports and a strong liaison with primary care and voluntary groups.

3. In-patient detoxification should take place only if strongly indicated, it should normally be brief, often crisis-ameliorating, and involve prompt action by social agencies. Out-patient detoxification should be considered as an alternative.

4. Future legislation should support the role of the family and non-statutory agencies. Support could be supplied both by voluntary (e.g. AlAnon) and statutory (e.g. counsellor, social worker) workers. Spouses often enable drinking in their partners, sometimes for neurotic reasons, but often because of the social and financial stigmas attached to separation.

5. Government should gradually shift to alternative sources of taxation whilst keeping the real price of alcohol high. Profits from the sale of alcohol could go directly to finance housing, education, health promotion schemes and job creation, thus avoiding central manipulation.

6. The courts should support abstinence via the probation option. Convicted alcoholics should have to report to some agency, such as a Garda station, late in the day. Barring orders should be strictly enforced. The association of glamour and sex with alcohol in advertisements should be rendered illegal and subject to strong penalties. Banning of advertisements would probably not work. An experiment in British Columbia was thwarted by the reception of U.S. television stations for over the border, and the U.S.S.R., which has no advertisements, has a significant alcohol problem.

7. The permitted alcohol level for qualified drivers should be reduced to $50 \mathrm{mgs} .100 \mathrm{ml}$. of blood and to zero for learner drivers and for the first three years after passing the driving test. Persons supervising learner drivers should not have consumed alcohol within 24 hours. Inebriated persons who are considered by the Gardaí to be a danger to themselves or others could be admitted for an initial 24 hours involuntarily (if necessary) and held for up to one week if this is deemed medically advisable. Such admissions need not in the first instance be to a hospital, although extended admissions probably should be.

8. Sales to minors should be the subject of regular criminal proceedings. Our public houses are full of under-age drinkers.

9. The excess morbidity among women from alcohol should be the subject of an educational drive, and alcoholic beverages should carry a warning about drinking during pregnancy.

10. Consideration should be given to prosecution for those serving alcohol to inebriated persons.

11. Finally, there should be a National Alcohol Committee with teeth which should be suitably composed and charged with supervising the application of the above recommendations.

Brian O'Shea, M.B., B.Ch., M.R.C.Psych.,
Consultant Psychiatrist,
Eastern Health Board,
Newcastle Hospital,
Greystones,
Co. Wicklow.

References

1. Reid ALA, Webb GR, Hennrikus D, et al. Detection of patients with high alcohol intake by general practitioners. Br Med J 1986; 293: $735-737$.

2. Taylor CL, Passmore N, Kilbane P, Davies R. Prospective study of alcohol-related admissions in an inner-city hospital. Lancet 1986; ii: $265-268$.

3. Rigby JC, Oswald AG. An evaluation of the performing and recording of physical examinations by psychiatric trainees. $\mathrm{Br} \mathrm{J}$ Psychiat 1987; 150: 533-535.

4. World Health Organisatioin. International Classification of Diseases. 9th revision. Geneva: WHO, 1978.

5. O'Shea B. Alprazolam: just another benzodiazepine? Ir J Psychol Med 1989; 6: 89-94.

\section{Substance misuse among psychiatric hospital inpatients}

Sir, - I wish to report an error and omission in this paper ${ }^{1}$. Although it had been the intention to diagnose drug-induced mental disorder only where there was corroborating chemical evidence this did not prove to be practicable and, as was described in the preliminary report of this work" the "diagnosis depended mainly on the history of substance abuse. .."

The reference to the letter ${ }^{2}$ was inadvertently omitted.

Bankole A Johnson, Senior Registrar, Wycombe General Hospital, High Wycombe, Bucks HP11 2TT.

\section{References}

1. Johnson BA. Substance misuse among psychiatric hospital inpatients. Ir J Psychol Med 1990; 7: 114-117.

2. Cohen, SI, Johnson K. Psychosis from alcohol or drug abuse [letter]. Br Med J 1988; 297: 1270-71. 